\title{
Low-tension gas process in high-salinity and low-permeability reservoirs
}

\author{
Alolika Das $^{1} \cdot$ Nhut Nguyen ${ }^{1} \cdot$ Quoc P. Nguyen ${ }^{1}$
}

Received: 28 November 2019 / Published online: 6 May 2020

(c) The Author(s) 2020

\begin{abstract}
Polymer-based EOR methods in low-permeability reservoirs face injectivity issues and increased fracturing due to near wellbore plugging, as well as high-pressure gradients in these reservoirs. Polymer may cause pore blockage and undergo shear degradation and even oxidative degradation at high temperatures in the presence of very hard brine. Low-tension gas (LTG) flooding has the potential to be applied successfully for low-permeability carbonate reservoirs even in the presence of high formation brine salinity. In LTG flooding, the interfacial tension between oil and water is reduced to ultra-low values $\left(10^{-3} \mathrm{dyne} / \mathrm{cm}\right)$ by injecting an optimized surfactant formulation to maximize mobilization of residual oil post-waterflood. Gas (nitrogen, hydrocarbon gases or $\mathrm{CO}_{2}$ ) is co-injected along with the surfactant slug to generate in situ foam which reduces the mobility ratio between the displaced (oil) and displacing phases, thus improving the displacement efficiency of the oil. In this work, the mechanism governing LTG flooding in low-permeability, high-salinity reservoirs was studied at a microscopic level using microemulsion properties and on a macroscopic scale by laboratory-scale coreflooding experiments. The main injection parameters studied were injected slug salinity and the interrelation between surfactant concentration and injected foam quality, and how they influence oil mobilization and displacement efficiency. Qualitative assessment of the results was performed by studying oil recovery, oil fractional flow, oil bank breakthrough and effluent salinity and pressure drop characteristics.
\end{abstract}

Keywords Enhanced oil recovery $\cdot$ Foam $\cdot$ Microemulsion $\cdot$ Carbonate $\cdot$ High salinity $\cdot$ Low permeability

\section{Introduction}

Conventional alkali-polymer (AP), surfactant-polymer (SP) and alkali-surfactant-polymer (ASP) flooding methods have limited success in carbonate formations because of typical high reservoir salinity, low permeability and complex rock-fluid interactions. The use of polymer is restricted due to plugging and shear degradation, particularly for very tight carbonate reservoirs (Farajzadeh et al. 2015). Lower molecular weight polymer might be a solution, but higher concentration would be required to achieve an equivalent viscosity, which might impact the economic feasibility of

Edited by Yan-Hua Sun

Quoc P. Nguyen

quoc_p_nguyen@mail.utexas.edu

$1 \quad$ Hildebrand Department of Petroleum and Geosystems Engineering, University of Texas at Austin, 200 E. Dean Keeton, Austin, TX 78712, USA the process. Although finding a suitable surfactant at high salinities is possible, relatively high viscosity of oleic phase and oil-water emulsions compared to the displacing aqueous phase prompt the use of a mobility control agent.

Low-tension gas (LTG) flooding process replaces polymers with foam, typically generated with an injected gas such as nitrogen, $\mathrm{CO}_{2}$ or hydrocarbon gases. The process utilizes a low-injection-rate strategy to better suit the lowpermeability carbonate rocks. Ideally, the surfactant is chosen such that it can simultaneously generate foam and lower the interfacial tension. In practice, two (or more) surfactants with different foaming and emulsifying effectiveness are utilized in the process. The low-IFT surfactant reduces the interfacial tension between water and oil to low levels (less than $10^{-3}$ dyne $/ \mathrm{cm}$ ) and thus mobilizes residual oil after waterflood, whereas the foaming surfactant enhances propagation of foam that controls the mobility of the displacing phases (i.e., gas and surfactant solution) for better displacement efficiency. Alkali is not normally used in LTG flooding 
in carbonate reservoirs because it causes precipitation in the presence of divalent ions.

Although aqueous foam for gas mobility control in gasimproved or enhanced oil recovery processes have been studied extensively at both laboratory and field scales, the novel concept of combining ultra-low IFT and mobility control by foam is yet to be developed to be applied efficiently on the field scale. Kamal and Marsden (1973) were one of the first to test alkaline-surfactant-gas (ASG) flooding in high-permeability (24 D) sandpacks, by injecting micellar chemical slugs and foam alternately to study the impact in tertiary and secondary recovery processes. The oil recovery values were similar to those observed in polymer flooding under similar conditions, proving that foam might be more economical than polymer solutions. Lawson and Reisberg (1980) investigated the alternate injection of micellar surfactant solution slugs (prepared in $900-14,000 \mathrm{ppm} \mathrm{NaCl}$ solution) and nitrogen gas in sandstone $(450-500 \mathrm{mD})$ and carbonate $(9-70 \mathrm{mD})$ outcrop cores. It was found that mobility control and oil recovery for the carbonate cores were higher than polymer flooding at the same conditions. Li et al. (2008) used foam as a mobility control agent instead of polymer for a typical ASP process to recover high-viscosity (266 cP) oil from $40 \mathrm{D}$ and $200 \mathrm{D}$ sandpacks. The sweep efficiency was increased with SAG compared to waterflood or water altering gas (WAG). Some of the earliest research in this field was conducted by Srivastava et al. (2009), Srivastava (2010), Srivastava and Nguyen (2010) who developed the design for ASG flooding (a precursor to LTG flooding) in both sandstone and dolomite outcrop cores of medium permeability. They proved the effectiveness of ASG flooding in providing mobility control even in the absence of any injected polymer. ASG flooding showed higher recovery than ASP flooding, with lower-pressure gradients. The key injection parameters investigated were the effect of permeability on recovery (higher permeability gave better recovery), effect of system pressure, type of gas, type of surfactant, foam quality, surfactant slug size and foam drive on recovery. Cottin et al. (2012) studied ASG flooding in coreflooding experiments in $100 \mathrm{mD}$ carbonate cores, for $230,000 \mathrm{ppm}$ connate brine. Nitrogen (in the case of dead oil) or methane (in the case of live oil) was co-injected with the surfactant to create foam for mobility control. Softened brine was used for slug and drive injection with alkali used to reduce surfactant retention. Oil recovery of $76 \%-80 \%$ was reported. Szlendak et al. (2013, 2016) tested the applicability of the LTG method for tertiary recovery in low-permeability formations $(2-35 \mathrm{mD})$ and found that the highest oil recovery was obtained when the injected foam quality (volumetric gas fraction in the injected gas and slug/drive mixture) used was $50 \%$. The effect of simultaneous injection versus alternating injection of surfactant solution and gas on the oil recovery and pressure drop profiles was also investigated. Their research was conducted using low-salinity brine without any divalent cations and in the presence of alkali.
The first field test to employ combined chemical and foam flooding was reported by Wang et al. (2001) for tertiary oil recovery at the Daqing oilfield in China. Residual oil saturation of $49 \%$ was achieved after previous waterflood and WAG injections. For the EOR stage, co-injection of chemical (surfactant and polymer in $12,000 \mathrm{ppm}$ of $\mathrm{NaOH}$ ) and gas $(25 \%$ foam quality) slugs was started. Additional $16.7 \%$ of original oil in place (OOIP) was recovered after 44 months using the combined EOR method.

Review of past work shows foam flooding or micellar foam flooding experiments were mostly conducted for reservoirs with low temperatures (below $50{ }^{\circ} \mathrm{C}$ ), moderate permeability and low formation brine salinity and low concentration of divalent cations. Very little research has yet been conducted for application in carbonate reservoirs with low permeability and very high formation brine salinity. The present work extends the application envelope of the LTG process to such carbonate reservoirs. This process has been studied experimentally for a carbonate reservoir in the Middle East with low permeability, moderate temperature $\left(69^{\circ} \mathrm{C}\right)$ and very high formation water salinity [ 200,000 ppm total dissolved solids (TDS)], with 19,000 ppm TDS of divalent cations $\left(\mathrm{Ca}^{2+}\right.$ and $\left.\mathrm{Mg}^{2+}\right)$. The main objective of this work is to understand the interrelationship between microemulsion, oil, surfactant and foam in the reservoir during LTG flooding, at both microscopic and macroscopic levels. The first step of this study attempts to develop and characterize a surfactant formulation to create in situ ultra-low IFT conditions in the reservoir. The properties of the microemulsion generated and their impact on foam stability are studied to analyze the mechanisms of LTG flooding at a microscopic level. The behavior of LTG process in lowpermeability, high-salinity reservoirs on a macroscopic scale are studied by means of coreflooding experiments. The main injection parameters studied for this purpose are (1) surfactant concentration in the injected slug, (2) injected slug salinity and (3) injected foam quality and their effect on the IFT reduction, oil mobilization and mobility control. Injection foam quality is directly related to gas mobility, in situ fluid saturation, fluid velocities and pressure gradients across the core. It also affects dispersion which in turn influences the in situ salinity profile which is crucial for IFT reduction. The key focus is the interrelation of surfactant concentration and foam quality, and its impact on oil mobilization and displacement efficiency.

\section{Materials and experimental procedures}

Crude oil Dead crude oil used for experiments was found to have a viscosity of $1.2 \mathrm{cP}$ and density of $45^{\circ} \mathrm{API}$ at the reservoir temperature of $69^{\circ} \mathrm{C}$.

Outcrop cores Outcrop cores of 1.5 inches in diameter and 12 inches in length were obtained by drilling Indiana 
limestone slabs of suitable permeability. Cleaned cores were dried for 30 days at $120^{\circ} \mathrm{C}$ to remove all excess water.

Synthetic brine The reservoir under study is under matrix water injection using produced water and complemented by fresh water from nearby source. Respective compositions of synthetic formation brine, produced brine and freshwater are shown in Table 1. For the experiments, a combination of the synthetic produced brine and synthetic fresh water was used to obtain a range of salinity for microemulsion phase behavior tests and respective injected salinities for waterflood brine, chemical slug and drive.

\subsection{Aqueous stability and microemulsion phase behavior tests}

Microemulsion phase behavior experiments were carried out at $69{ }^{\circ} \mathrm{C}$ using a series of glass pipets with incremental electrolyte differences to obtain microemulsion data versus total dissolved solids (TDS) (in ppm) values. Each pipet contains a concentrated stock solution of surfactant mixed with different brine solutions to achieve the desired salinity. Before adding crude oil to pipets, an aqueous stability assessment was performed to determine the clarity and homogeneity of all dispensed aqueous solutions. After dispensing in each tube, aqueous volumes were settled for $24 \mathrm{~h}$, and the aqueous stability was assessed by visually inspecting any cloudiness and/or phase separation. Aqueous stability is important to ensure a stable surfactant slug for injection. An experiment containing any phase separation or precipitation in the aqueous phase at and slightly beyond optimal salinity fails this screening. After assessing aqueous stability, crude oil was added to pipets, and pipets were heat-sealed, cooled and slowly inverted several times to allow oil and aqueous phase mixing. Pipets were then incubated in a convection oven at $69{ }^{\circ} \mathrm{C}$. The fluids in pipets were remixed every few hours to ensure that equilibrium is attained faster. Fluid interfaces were recorded after equilibration time.

Selection of surfactants suitable for our extreme reservoir conditions was based on extensive literature survey of past work in the field of high-temperature, high-salinity surfactant EOR. The three classes of surfactants chosen for our work were: carboxylates, internal olefin sulfonates (IOS) and alkyl polyglucosides (APG).

Carboxylates Carboxylate surfactants combined with IOS are the main contributors to microemulsion formation and lowering of oil-water IFT. The main factors to be considered while selecting carboxylate surfactants are:

- Hydrophobe length controls the hydrophobicity and hydrophile-lipophile balance (HLB). Larger hydrophobes are needed for heavier oils and at higher temperature.

- Branching of tail group improves aqueous stability of surfactant in brine solution by reducing macroemulsions and gels.

- The addition of ethylene oxide (EO) groups to the surfactant structure increases the hydrophilicity and raises the optimum salinity. Propylene oxide (PO) groups increase the hydrophobicity and lower the optimum salinity. The right combination and number of EO and PO groups enables us to attain lowest IFT (optimum salinity in Type III) and good aqueous stability at a desired salinity value.

- Type and position of polar head group impacts the microemulsion phase behavior

Solairaj (2011) tested Guerbet alkoxy carboxylates (GAC) on carbonate reservoirs with high connate brine salinity $\left(213,000 \mathrm{ppm}\right.$ with $21,500 \mathrm{ppm}$ of $\mathrm{Ca}^{2+}$ and $\mathrm{Mg}^{2+}$ ions) and at $100{ }^{\circ} \mathrm{C}$. GAC surfactants were found to be stable without alkali, over a wide range of $\mathrm{pH}$. They could reduce oil-water IFT when combined with IOS and alkyl benzene sulfonates (ABS). Adkins et al. (2012) also studied novel large hydrophobe carboxylate surfactants prepared by the carboxymethylation of large Guerbet alkoxylates for high-salinity applications. These surfactants could be used without alkali; they were stable at high temperature and in high salinity, hard brine; and they could achieve ultra-low IFT with reduced microemulsion viscosity. Lu et al. (2014) successfully tested Guerbet carboxylates at high-temperature, high-salinity conditions using phase behavior, aqueous stability and coreflooding tests. Upamali et al. (2016) reported up to

Table 1 Synthetic brine compositions

\begin{tabular}{lrrrrrr}
\hline Sample & \multicolumn{2}{l}{ Component, ppm } & & & \multicolumn{1}{c}{ TDS, ppm } \\
\cline { 2 - 6 } & \multicolumn{1}{c}{$\mathrm{Na}^{+}$} & $\mathrm{Ca}^{2+}$ & $\mathrm{Mg}^{2+}$ & $\mathrm{Cl}^{-}$ & $\mathrm{SO}_{4}^{2-}$ \\
\hline Aquifer brine & 2720 & 510 & 230 & 4420 & 1820 & 10,000 \\
Formation brine & 62,990 & 16,220 & 2270 & 132,200 & 210 & 214,000 \\
Produced water & 44,430 & 12,580 & 3320 & 100,000 & 540 & 160,000 \\
\hline
\end{tabular}


$90 \%$ oil recovery post-waterflood at $68^{\circ} \mathrm{C}$ using a blend of ethoxylated propoxylated carboxylates and IOS. Abalkhali et al. (2019) reported tertiary oil recovery up to $90 \%$ in ASP corefloods using a blend of ethoxylated propoxylated carboxylates and IOS for carbonate rock at $100{ }^{\circ} \mathrm{C}$ and 60,000 ppm salinity.

Internal olefin sulfonates Internal olefin sulfonates (IOS) are highly suitable for surfactant EOR because of good oil solubilization properties and their ability to reduce liquid crystals and gels (Levitt et al. 2009; Barnes et al. 2008, 2010). IOS are prepared by oligomerization of ethylene by olefin metathesis process, which generates a product with a range of different carbon lengths (for example $\mathrm{C}_{15-18}$ or $\mathrm{C}_{24-28}$ ) and a range of internal, double bond positions. This structure makes IOS more suitable for EOR applications at high temperature. The degree of branching in the carbon chain and the degree of sulfonation are important factors which determine the IOS properties, and can be used to tailor IOS performance (Barnes et al. 2008). IOS surfactants, with their twin-tailed, branched structure, show good emulsification in the presence of high-salinity brine (Solairaj 2011). Barnes et al. (2010) studied four ranges of carbon chain lengths for IOS: $\mathrm{C}_{15-18}, \mathrm{C}_{19-23}, \mathrm{C}_{20-24}$ and $\mathrm{C}_{24-28}$. The higher-carbon chain ranges were associated with higher solubilization parameters. $\mathrm{C}_{24-28}$ IOS was the most hydrophobic with high solubilization parameters at low salinities, and $\mathrm{C}_{15-18} \mathrm{IOS}$ was the most hydrophilic with low solubilization parameters at high salinities (Buijse et al. 2010; Solairaj 2011).

The main drawback in using IOS surfactants is their inability to withstand hard brine with high concentration of divalent cations (Kamal et al. 2017; Southwick et al. 2018). Therefore, a third class of surfactant (alkyl polyglucoside) was required for high-salinity, hard brine conditions which could improve the aqueous stability of the surfactant formulation.

Alkyl polyglucosides These surfactants are nonionic, derived from sugars and fatty alcohols. The hydrophilic head is composed of glucose structure, and the hydrophobic end consists of alkyl groups. The nonionic nature makes them resilient to high concentration of divalent cations in brine. Ghosh and Obassi (2013) investigated alkyl polyglucoside (APG) surfactants using aqueous stability, microemulsion phase behavior and coreflooding tests which proved their salinity tolerance up to $263,000 \mathrm{ppm}$ and $104^{\circ} \mathrm{C}$ in carbonate reservoirs. Iglauer et al. (2004) also successfully studied APGs for microemulsion phase behavior experiments at $30{ }^{\circ} \mathrm{C}$ and 110,000 ppm salinity. Das et al. (2016) were the first to successfully demonstrate the applicability of APG surfactants in LTG flooding in high-salinity (above 200,000 ppm) environments.
The selected surfactant formulation for our study consisted of ethoxylated propoxylated carboxylate (Huntsman XOF320C), $\mathrm{C}_{15-18}$ IOS (Shell Enordet O332) and alkyl polyglucoside (Dow Triton CG 650) in the ratio 2:2:1. The same surfactant ratio was used for all experiments in this work. The total surfactant concentration used did not affect the Type III microemulsion salinity range or the optimum salinity. The carboxylate and IOS were identified to be the primary surfactants responsible for microemulsion formation, while APG was used to stabilize the formulation in the presence of high-salinity brine. The phase behavior results showed Winsor Type III microemulsion between 130,000 and 155,000 ppm. Optimum Type III salinity was at $148,000 \mathrm{ppm}$. The optimum solubilization ratio was 10.5 , which gives IFT $\sigma^{*}=2.7 \times 10^{-3}$ dyne $/ \mathrm{cm}$ using Chun Huh equation (Huh 1983). Aqueous samples showed no turbidity or precipitation.

\subsection{Characterization of microemulsion effect on foam stability}

For our coreflood designs, the concept of negative salinity gradient is used as prescribed by several researchers (Nelson and Pope 1978; Pope et al. 1979; Hirasaki et al. 1983; Flaaten et al. 2008; Levitt et al. 2009). According to this concept, during tertiary recovery, the high-salinity slug is injected first containing the surfactant which will facilitate Type III microemulsion conditions. After the short slug, the lower salinity drive is injected which can facilitate Type I conditions in the core. The slug mainly helps to mobilize the residual oil after waterflood, while the drive assists in efficient displacement of this mobilized oil by contributing to foam stability.

For our coreflood experiments, the slug injection salinity is the optimum Type III during microemulsion phase behavior. But, we need to identify the exact drive salinity (which will facilitate Type I microemulsion) which needs to be injected. For this purpose, the Type I microemulsion properties are studied and correlated with foam stability.

Different properties of the Type I microemulsion such as oil-water IFT, viscosity, micelle particle size and dynamic foam stability were measured. After equilibrating with oil, the Type I microemulsion phase was extracted and excess oil phase removed. This extracted microemulsion phase was used for all measurements.

The IFT between oil and water for the extracted microemulsion phase was measured by a spinning drop tensiometer. Microemulsion viscosity was measured using a rheometer, by studying the flow in the annular space between two concentric cylinders.

Dynamic light scattering (DLS) method was used to measure the micelle size using an instrument from Malvern. The equilibrated microemulsion samples were diluted 
to $3 \mathrm{wt} \%$ and $6 \mathrm{wt} \%$ concentration using brine of the same salinity as the microemulsion sample salinity. This enabled easier detection of particle size by the instrument, because the particle concentration was reduced while maintaining the same particle size.

For bulk foam stability tests, nitrogen gas was bubbled through a small volume of the microemulsion sample contained in a graduated glass cylinder. Gas flow rate was maintained at $25 \mathrm{~mL} / \mathrm{min}$. The foam column continued to rise until the rate of foam generation was balanced by the rate of foam lamella collapse by capillary drainage. The equilibrium foam height was noted for each sample. This value was normalized using the foam height generated by surfactant solution of similar concentration in deionized (DI) water without the presence of oil.

\subsection{Coreflood experiments}

The selected surfactant formulation was tested in the outcrop limestone cores using the simultaneous injection of $\mathrm{N}_{2}$ gas and surfactant solution. The average permeability of all cores was less than $10 \mathrm{mD}$. Coreflood procedure has been described in detail by Srivastava et al. (2009; Srivastava and Nguyen 2010) and Szlendak et al. (2013, 2016). Experimental properties are summarized in Table 2. Table 3 summarizes the corefloods performed, their injection parameters and the objectives for each study.

Table 2 Properties of coreflood experiments

\begin{tabular}{ll}
\hline Rock type & Limestone \\
Length, in & 12 \\
Diameter, in & 1.5 \\
Temperature, ${ }^{\circ} \mathrm{C}$ & 69 \\
Backpressure, psi & 1000 \\
Waterflood injection rate, ft/day & 3 \\
Slug/drive injection rate, ft/day (liquid and gas) & 3 \\
Gas type & $\mathrm{N}_{2}$ \\
Waterflood salinity, ppm & 160,000 \\
Drive salinity, ppm & 100,000 \\
Slug size, PV (liquid) & 0.5 \\
\hline
\end{tabular}

According to Nelson and Pope (1978), if effective mobility control is maintained, only a short period of ultra-low IFT conditions in the reservoir is sufficient for effective oil emulsification and mobilization. Accordingly, slug (liquid) was injected for 0.5 pore volumes (PV) right after water flooding. Slug injection was followed by the injection of drive solution with $0.2 \mathrm{wt} \%$ APG (Table 2). The primary function of the drive is to provide surfactant for foam generation and mobility control, such that the oil mobilized during ultra-low IFT conditions in the core can be displaced efficiently. The drive injection salinity was determined from microemulsion characterization studies (discussed in the Sect. 4). Slug and drive phases were always injected at a fixed total rate of $3 \mathrm{ft} /$ day (Table 2). The same total injection rate was maintained for all the corefloods to maintain consistency. This drive stage was continued until no more oil was produced in the effluent. Experimental properties measured were oil recovery, oil cut, pressure drop and effluent salinity.

Figure 1 shows a schematic of the vertical coreflood set up. Gas rate was calculated at reservoir temperature and pressure, and regulated by analog mass flow controller (MFC) from Brooks. A syringe pump (Quizix) was used to inject liquid. Deionized water pumped through the Quizix pump was injected into one end of the mineral oil (MO) accumulators. This helped direct the mineral oil to push the liquids (formation brine, waterflood brine, slug and drive solutions) into the inlet of the core. To drive the crude oil to the core inlet, deionized water was directly injected at one end of the crude oil accumulator. Backpressure regulators were used in the coreflood set up to maintain the system pressure. Differential and absolute pressure transducers were used to measure sectional and overall pressure drop across the core. Gas and liquid were combined in a T-connection just before the inlet of the core. Foam pre-generator was not used in the setup. Fractional collector at the outlet of the core was used to collect effluent samples at regular intervals.

Table 3 Coreflood injection parameters

\begin{tabular}{lllllll}
\hline Flood & Porosity, $\%$ & $\begin{array}{l}\text { Permeability, } \\
\mathrm{mD}\end{array}$ & Slug salinity, ppm & $\begin{array}{l}\text { Slug surfactant con- } \\
\text { centration, wt } \%\end{array}$ & $\begin{array}{l}\text { Foam qual- } \\
\text { ity, } \%\end{array}$ & Objective \\
\hline 1 & 20 & 7.3 & 148,000 & 1.00 & 50 & Reference flood \\
2 & 23 & 10.4 & 130,000 & 1.00 & 50 & Effect of slug injection salinity \\
3 & 27 & 9.0 & 148,000 & 0.50 & 50 & Effect of slug surfactant concentration \\
4 & 24 & 8.4 & 148,000 & 0.25 & 30 & Effect of lower injected foam quality \\
\hline
\end{tabular}




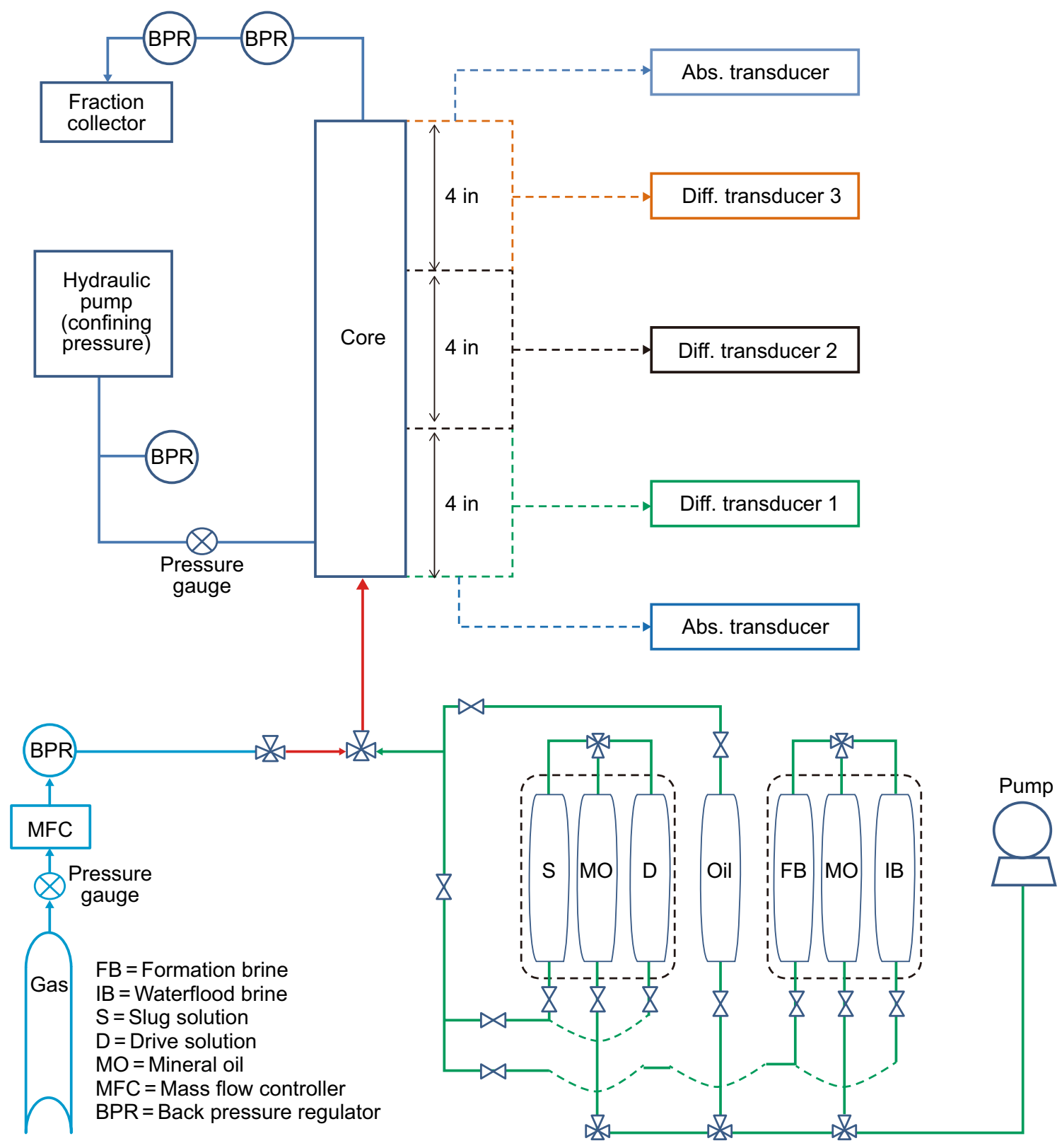

Fig. 1 Schematic of vertical coreflood set up

\section{Analytical concepts used to evaluate coreflood experiments}

\subsection{Gas saturation $\left(S_{\text {gas }\left.\right|_{t_{D 1}}}\right)$}

An estimate of the in situ gas saturation can be made from the effluent salinity profile (Szlendak et al. 2013). The following assumptions should be taken into account: (1) Complete contact exists between the displacing aqueous phase (slug/drive) and the displaced aqueous phase (resident brine); (2) The drive salinity has no effect on the mixing between the slug and the formation brine. The dimensionless time $t_{\mathrm{D} 1}$ (in terms of injected pore volumes of liquid), at which the effluent salinity reaches the midpoint value of the slug and formation brine, can be used to determine the values of different phase saturation values at breakthrough point. The higher gas saturation indicates decreased gas permeability, better foam propagation and better process tolerance to high oil saturation during the formation of the oil bank. The equations used for calculating gas saturation at $t_{\mathrm{D} 1}$ are as follows. 
$C_{\mathrm{m}}=\frac{C_{\mathrm{r}}+C_{\mathrm{s}}}{2}$

$S_{\text {water }_{t_{\mathrm{D} 1}}}=t_{\mathrm{D} 1}$

$S_{\text {total }}=S_{\text {water }}+S_{\text {gas }}+S_{\text {oil }}$

$S_{\left.\mathrm{gas}\right|_{\mathrm{D} 1}}=1-S_{\mathrm{water}{ }_{\mathrm{D} 1}}-S_{\mathrm{oill}_{{ }_{\mathrm{D} 1}}}$

$S_{\text {oil }_{l_{\mathrm{D} 1}}}=S_{\text {oil }_{2 \mathrm{PV} \text { water flood }}}-\Delta S_{\mathrm{LTG} \text { flood }\left.\right|_{\mathrm{L} 1}}$

where $C_{\mathrm{r}}$ and $C_{\mathrm{s}}$ refer to the brine TDS values of $160,000 \mathrm{ppm}$ and $148,000 \mathrm{ppm}$, respectively; $t_{\mathrm{D} 1}$ is the dimensionless time in terms of injected liquid pore volumes at which the effluent salinity reaches $154,000 \mathrm{ppm}\left(C_{\mathrm{m}}\right)$; $S_{\text {water }}$ at this time is equal to $t_{\mathrm{D} 1}$ [Eq. (2)]. $S_{\text {oil }}$ at $t_{\mathrm{D} 1}$ is calculated from mass balance by measuring the oil recovered after waterflood till $t_{\mathrm{D} 1}$ [Eq. (5)].

\subsection{Pore volumes available for mobile oil $\left(P V_{M O}\right)$}

After the secondary recovery by waterflood, the mobile oil is removed from the pores with lower capillary pressure. When gas (non-wetting phase irrespective of rock wettability) is injected during LTG flooding, it will occupy the bigger pores (earlier occupied by mobile oil) while increasing liquid flow to smaller, earlier inaccessible pores. Conn et al. (2014) and Nguyen et al. (2005) found that when foam is injected, the liquid is diverted to the lower-permeability zones, because the larger permeability pores are occupied by gas. Liquid diversion caused by foam is a well-known phenomenon in matrix acidizing where foam is used as an acid diverter (Kennedy et al. 1992; Nguyen et al. 2009). The concept of $P V_{\mathrm{MO}}$ is used to quantify these large pores. $P V_{\mathrm{MO}}$ is defined as $P V_{\mathrm{MO}}=S_{\mathrm{oi}}-S_{\text {orw }}$ (initial oil saturation minus oil saturation post-water flood). The in situ gas saturation maybe be different (higher or lower) from the injected foam quality. $P V_{\mathrm{MO}}$ may make up $25 \%-30 \%$ total pore volume in low-permeability rocks. $P V_{\mathrm{MO}}$ is also associated with size of oil bank, higher $P V_{\mathrm{MO}}$ translates to a short oil bank with high oil saturation. If the values of $S_{\text {gas } t_{\text {D1 }}}$ and $P V_{\mathrm{MO}}$ are similar, it signifies that in situ gas saturation is high enough to enhance mobility control. High $\left.S_{\text {gas }}\right|_{t \mathrm{Dl}}$ to $P V_{\mathrm{MO}}$ ratio is generally an indicator of better mobility control and higher oil recovery (Szlendak et al. 2013).

\section{Results and discussion}

\subsection{Characterization of microemulsions and foam stability}

\subsubsection{Oil-water interfacial tension}

The IFT measurements between oil and water for the extracted microemulsion phase are shown for the salinity range of 80,000-120,000 ppm, which corresponds to Type I environment (Fig. 2).

Measured values for IFT range from $5.8 \times 10^{-2}$ dyne/ $\mathrm{cm}$ at $80,000 \mathrm{ppm}$ to $4.9 \times 10^{-3}$ dyne $/ \mathrm{cm}$. For most ASP floods, the Type III environment is preferred during slug injection to facilitate ultra-low IFT conditions. In our case, the surfactant slug will be injected at 148,000 ppm which corresponds to optimum Type III salinity and ultra-low IFT conditions $\left[2 \times 10^{-3}\right.$ dyne/cm as per Chun Huh equation (Huh 1983)]. The drive will be injected corresponding to Type I conditions. Therefore, the in situ salinity as a result of mixing between the two injection brines (slug and drive) should be as close as possible to ultra-low IFT conditions. From Fig. 2, we can see that for salinity equal to or higher than $100,000 \mathrm{ppm}$, the IFT conditions are close to the ultra-low range. Therefore, we can conclude than we have a very efficient surfactant formulation for reducing oil-water IFT to ultra-low values throughout the salinity range from slug $(148,000 \mathrm{ppm})$ to drive $(100,000 \mathrm{ppm})$. The expected oil recovery from corefloods should be high, with high rate of recovery even during the drive injection.

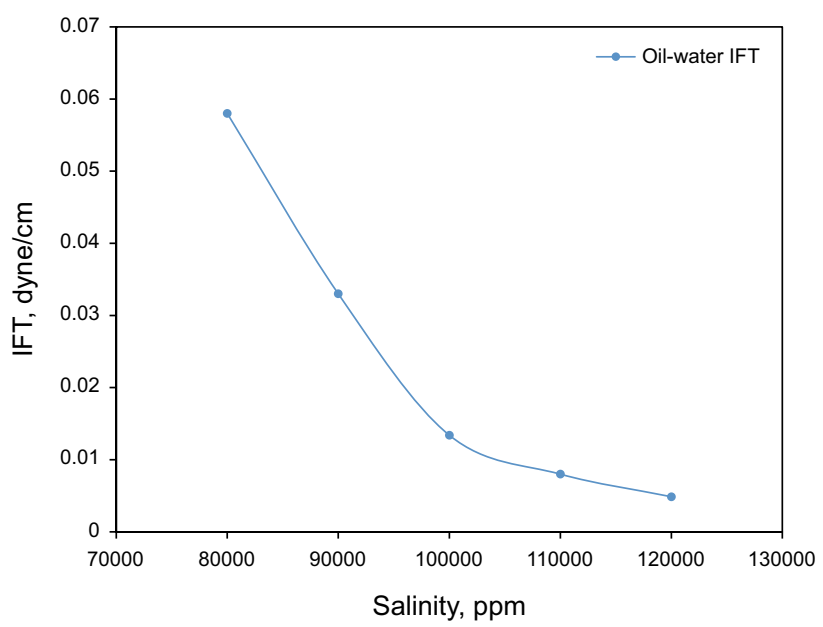

Fig. 2 Oil-water IFT at $69^{\circ} \mathrm{C}$ 


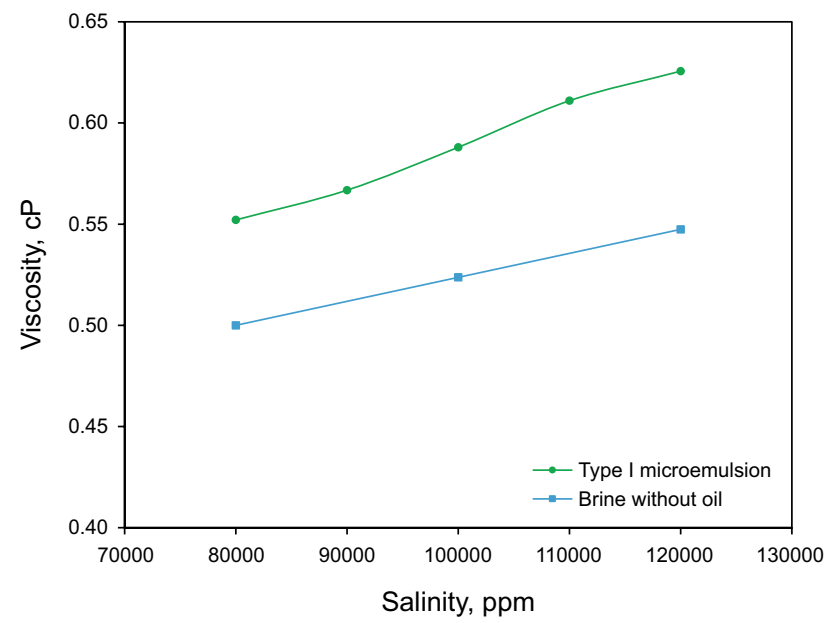

Fig. 3 Viscosity of Type I microemulsions at $69{ }^{\circ} \mathrm{C}$ and fixed shear rate of $10 \mathrm{~s}^{-1}$

\subsubsection{Microemulsion viscosity}

Figure 3 shows the viscosity properties of Type I microemulsion with increasing salinity. Within this salinity range, the microemulsion viscosity is closer to the brine viscosity than the oil viscosity $(1.2 \mathrm{cP})$. Microemulsion viscosity increases from 0.55 to $0.63 \mathrm{cP}$ in this salinity range. The brine viscosity (without oil and surfactant) also follows a similar trend. This is in accordance with the research on brine salinity by El-Dessouky and Ettouney (2002).

The presence of foam is accompanied by the reduction in total apparent fluid mobility for both the liquid and the gas phases (Balan 2013). The foam lamellae, which are stabilized by surfactants, help increase the apparent viscosity of the gaseous phase. Gas relative permeability is also decreased by the presence of trapped gas, which results in reduced mobile gas saturation. Thus, the gas mobility is reduced. On the other hand, increased gas saturation in the pores leads to reduced liquid saturation, and thus, the liquid permeability is also reduced. Now, if the liquid phase viscosity is further increased by the presence of microemulsions, the total liquid mobility will be further reduced. The higher microemulsion viscosity is therefore a positive contributor to higher foam stability. From Fig. 3, we can predict that higher microemulsion viscosity will result in better foam stability as compared to the lower viscosity of brine without microemulsion.

Since the microemulsion viscosity is not very high compared to the brine, it will also prevent phase trapping in the reservoir. The difference in viscosity of brine with different salinities will also affect the in situ mixing between brines and hence the in situ salinity gradient, which in turn will impact the IFT and the oil mobilization. The viscosity of the formation brine $\left(214,000 \mathrm{ppm}\right.$ at $\left.69^{\circ} \mathrm{C}\right)$ will be higher than the injected brines; hence, its mobility will be lower, which in turn will affect the mixing with the injected brines.

\subsubsection{Micelle size and concentration and effect on dynamic foam stability}

Micelles are colloid-like clusters which are formed by surfactant molecules, when the concentration of the surfactant in solution reaches a particular critical concentration (critical micelle concentration, CMC). For our experimental conditions, the surfactant concentration used is much higher than the CMC. The size of these micelles will be different in the presence and absence of oil. For Type I microemulsions, the micelles will consist of solubilized oil in the center radially surrounded by the hydrophobic tail of the surfactant molecules, while the hydrophilic heads of the surfactant molecules will be in contact with the aqueous solution.

Micelle concentration was calculated from the measurement of micelle size. Assuming monodisperse solution, the volume of the solubilized oil divided by the micelle particle volume gave the total number of micelles for each sample. This value divided by the total volume of the microemulsion gave the micelle concentration for each sample. Results are presented by normalizing the micelle concentration of each sample to that of the 80,000 ppm sample. Figure 4 shows the micelle size and concentration with increasing salinity. Metin et al. (2013) established a correlation that proved that the dispersion viscosity increases with size of nanoparticles. From Figs. 2 and 4, we can conclude that the microemulsion viscosity increased with the increase in micelle diameter. While Type I microemulsion viscosity could improve foam stability, there are other phenomena associated with oil-swollen micelles which could have detrimental effect on foam stability.

Figure 5 shows the results of the dynamic foam stability test. We can observe that the foam stability of Type I

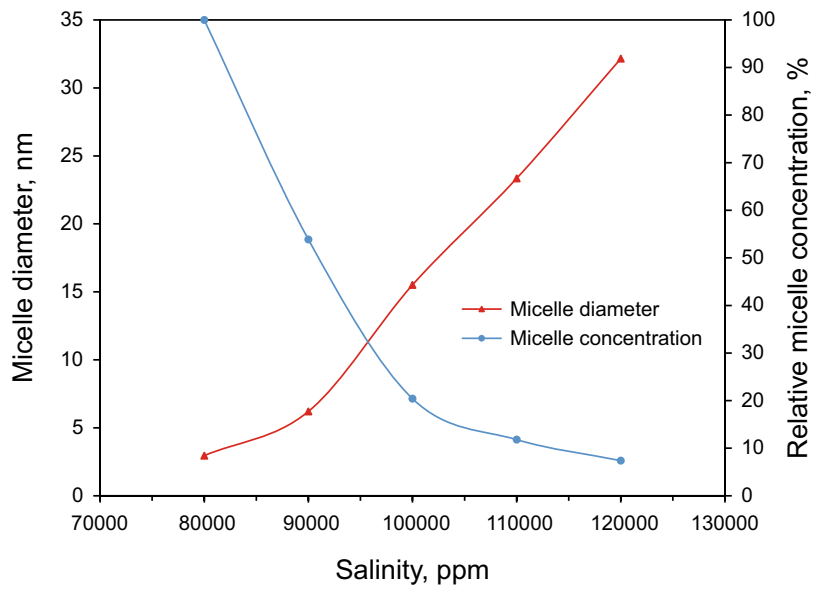

Fig. 4 Micelle size and concentration for Type I microemulsions 


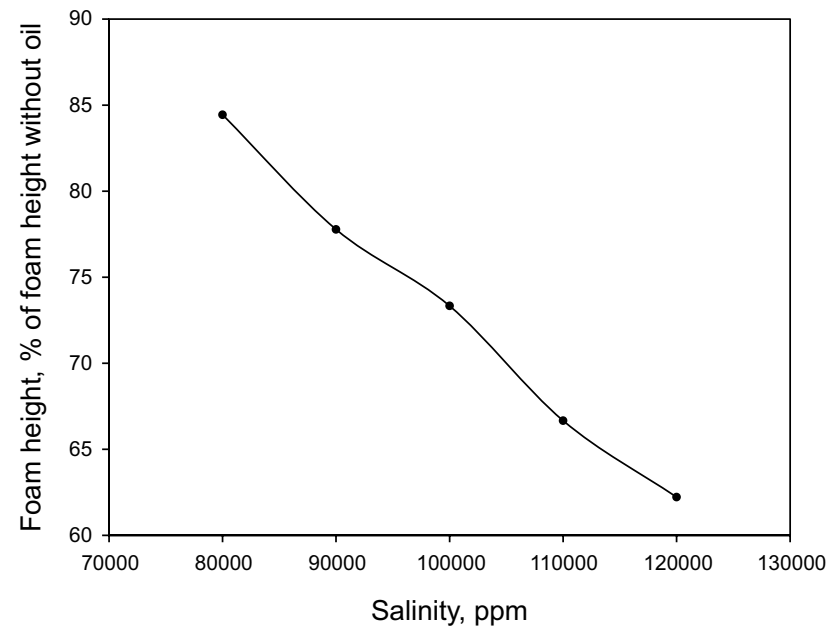

Fig. 5 Dynamic foam stability for Type I microemulsions

microemulsions decreases with an increase in salinity. The positive effect of increase in microemulsion viscosity on foam stability is not as significant as compared to the negative effect of solubilized oil.

Koczo et al. (1992) studied the effect of oil on foam stability. Oil affects the foam stability in two ways, as emulsified oil (macroemulsions) or as solubilized oil (microemulsions). The concept of pseudoemulsion film was an important one in the case of foam stability in the presence of emulsified oil (Manlowe and Radke 1990). The film between an approaching oil drop and the gas-liquid interface is called the pseudoemulsion film. If the pseudoemulsion film is unstable, the oil drop may spread on the gas-liquid interface and cause the lamella to rupture. If the pseudoemulsion film is stable, the emulsified oil may increase the stability of the foam because of accumulation of oil drops in the plateau borders. This accumulated oil drops decelerate the drainage of liquid through the network of plateau borders, thus improving the foam stability. As the oil volume fraction increases, the foam stability also increases.

Nikolov and Wasan (1989) and Nikolovet al. (1989) found that in micellar solutions, the foams are seen to undergo stepwise or stratified thinning because of the presence of ordered micellar structure within the lamellae. The ordered structures are formed because of restricted volume available to the liquid. This stratification phenomenon is observed for both anionic and nonionic surfactants. The stratification decelerates film drainage and enhances foam stability. When oil is solubilized within these micelles, the effective volume of the individual micelles is reduced. Thus, the inter-micellar repulsion between the oil-swollen micelles is lesser than the repulsion between micelles with no oil. This is quantified by the second virial coefficient of micellar solutions, the value of which is reduced in the presence of oil (Lobo et al. 1989). This hinders the stratification phenomenon and reduces the foam stability (as seen in Fig. 5). With increasing salinity, oil solubilization per micelle (as seen from micelle diameter) increases and the micelle concentration decreases (Fig. 4), further reducing the inter-micellar repulsion and decreasing the foam stability (Jong 2018).

From the microemulsion characterization experiments, we can conclude that choosing a lower injection salinity for the drive will lead to better foam stability. From the observations of the results from Figs. 4 and 5, we can choose the drive salinity to be $80,000 \mathrm{ppm}$ or even lower. But from the IFT results of Fig. 2, we see that only at 100,000 ppm, the oil-water IFT reaches close to ultra-low values. To have the best combination of ultra-low IFT and good foam stability, we therefore select the drive salinity to be $100,000 \mathrm{ppm}$ for all the subsequent oil recovery corefloods.

\subsection{Oil recovery from LTG corefloods}

Table 4 shows the initial oil saturation after primary drainage $\left(S_{\mathrm{oi}}\right)$, the residual oil saturations after waterflood $\left(S_{\text {orw }}\right)$ and the oil recovery by LTG flooding from coreflood experiments. Residual oil saturation values post-LTG flood ( $\left.S_{\text {orLTG }}\right)$ are tabulated. Residual oil saturations after waterflood $\left(S_{\text {orw }}\right)$ are quite consistent for the corefloods.

\subsubsection{Reference coreflood (Coreflood 1)}

Oil recovery and oil cut The reference coreflood was conducted using $1 \%$ surfactant concentration in the slug at the optimum Type III salinity of $148,000 \mathrm{ppm}$, co-injected with injected foam quality of $50 \%$, for both the slug and drive

Table 4 Summary of coreflood results

\begin{tabular}{lllllll}
\hline Coreflood & $S_{\text {oi }}, \%$ & $S_{\text {orw }}, \%$ & $\begin{array}{l}\text { Oil recovery, } \% \\
\text { ROIP }\end{array}$ & $\begin{array}{l}\text { Incremental recovery by LTG } \\
\text { flood, \% OOIP }\end{array}$ & $\begin{array}{l}\text { Total recovery after LTG } \\
\text { flood, \% OOIP }\end{array}$ & $\begin{array}{l}S_{\text {orLTG }} \% \\
1\end{array}$ \\
\hline 6 & 64 & 38 & 85 & 50 & 90.9 & 5.7 \\
3 & 60 & 34 & 80 & 45 & 88.4 & 89.8 \\
4 & 60 & 31 & 80 & 42 & 84 & 6.1 \\
\hline
\end{tabular}

ROIP means residual oil in place post-water flood; OOIP means original oil in place 
phases. The $50 \%$ injected foam quality was selected based on the studies by Srivastava et al. (2009), Srivastava (2010), Srivastava and Nguyen (2010) and Szlendak et al. (2013, 2016). These studies found that $50 \%$ foam quality was optimum for LTG flooding at high surfactant concentrations. Injecting at ultra-low IFT would be conducive to mobilizing the residual oil. Figure 6a shows that ultimate oil recovery of $85 \%$ ROIP was established after 3 injected pore volumes of liquid and gas $\left(t_{\mathrm{DT}}=3 \mathrm{PV}\right)$. In terms of $\%$ OOIP, the final recovery was $90.9 \%$. LTG flooding could recover an additional $50 \%$ of OOIP with remaining oil saturation of $5.7 \%$.
During LTG flooding, when the residual oil is mobilized because of the ultra-low IFT, the in situ oil saturation increases ahead of the surfactant front. With time, the oil saturation is high enough such that the oil mobility increases, and the mobilized oil starts advancing in the form of an oil bank. It is generally observed that when the pore volume available to mobile oil $\left(P V_{\mathrm{MO}}\right)$ is low, the oil bank is more elongated with a lower oil saturation $\left(S_{\mathrm{o}}\right)$. Figure $6 \mathrm{a}$ shows that almost $40 \%$ of ROIP is recovered by the end of slug injection, with a maximum oil cut of $50 \%$. Fractional flow of oil $\left(f_{\mathrm{o}}\right)$ remains high between $30 \%$ and $50 \%$ from 0.4
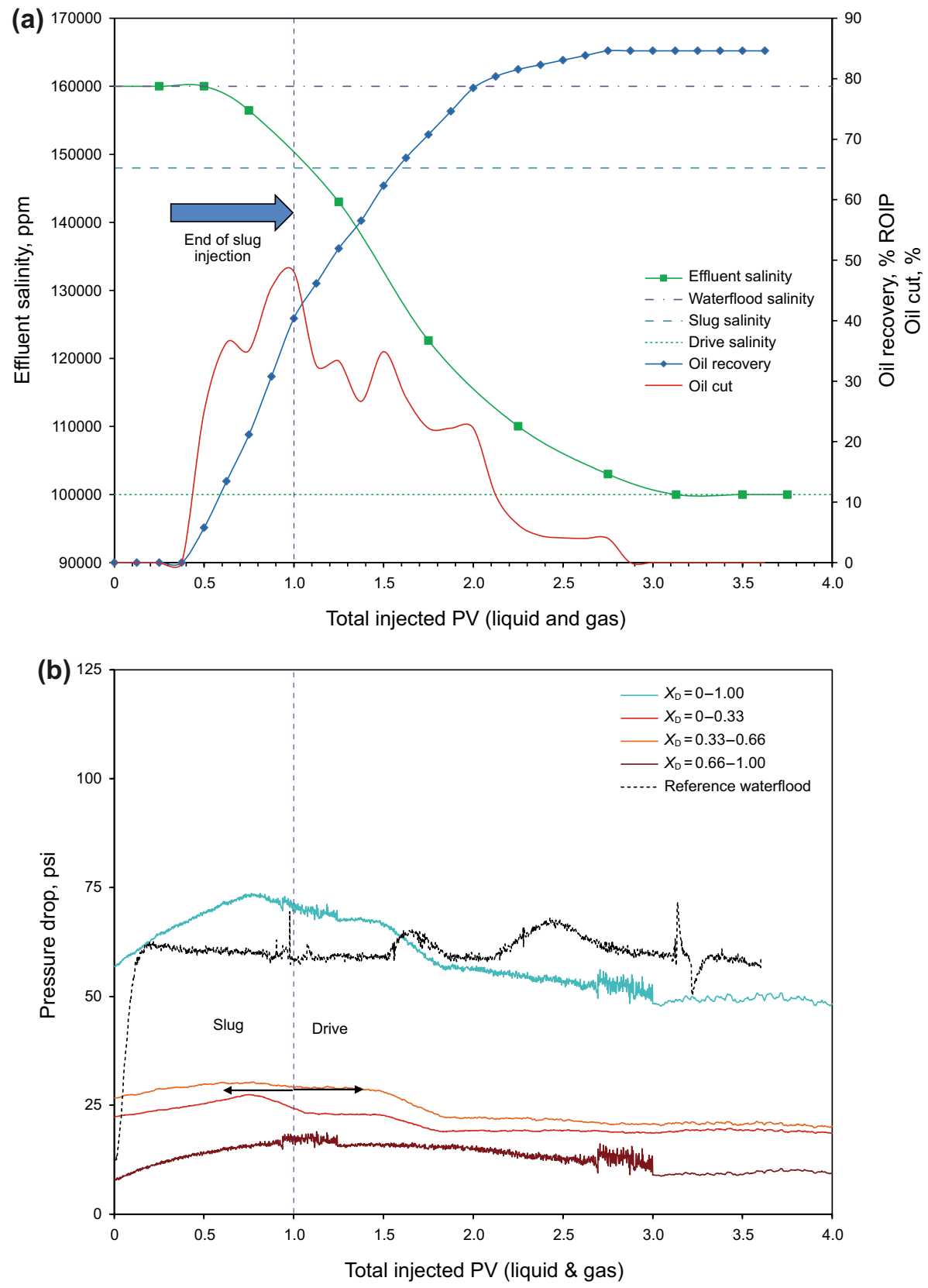

Fig. 6 a Oil recovery, oil cut and effluent salinity and $\mathbf{b}$ respective pressure drops for waterflood and Coreflood 1 
to $2 \mathrm{PV}$ by which time $80 \%$ of ROIP has been recovered. This is consistent with performance of ASP floods where high fractional flow of oil corresponds to the formation and propagation of a thick oil bank (oil bank with high $S_{\mathrm{o}}$ ).

Effluent salinity profile Figure 6a shows that the effluent salinity is midway between waterflood and slug salinity at $t_{\mathrm{DT}}=0.8 \mathrm{PV}$. This is also the point where the core enters the Type III microemulsion regime. The core remains in Type III salinity conditions from $t_{\mathrm{DT}}=0.8 \mathrm{PV}$ to roughly $1.6 \mathrm{PV}$, by the end of which almost $65 \%$ ROIP has been recovered. Thus, for LTG flooding the injection strategy should be designed in such a way that the in situ salinity conditions favor ultra-low IFT for a substantial amount of time. Beyond $t_{\mathrm{DT}}=1.6 \mathrm{PV}$, the salinity decreases until it reaches the drive salinity around $t_{\mathrm{DT}}=3 \mathrm{PV}$, by which time the ultimate recovery of $85 \%$ has also been attained.

Pressure gradient The initial stage of the LTG pressure curve is affected mainly by high oil saturation, which decreases the total apparent fluid mobility as the in situ oil saturation increases up from the residual oil saturation after waterflood. As the residual oil is mobilized and the oil bank advances through the core, the pressure drop increases steadily (Fig. 6b). As the oil bank moves out of each section, the oil saturation in that section decreases which results in a reduction in pressure. Note that all three sections of the core have the same length. A decrease in pressure drop in the upstream section is seen simultaneously with an increase in pressure drop in the downstream section. Successive increases in the sectional pressure drop curves indicate the formation and propagation of an oil bank through the core. It is seen that the core reaches steady-state pressure drop values in all sections by the time the ultimate oil recovery of $85 \%$ ROIP is attained $\left(t_{\mathrm{DT}}=3 \mathrm{PV}\right)$. Section 3 takes longer to reach steadystate pressure drop, which corresponds to the tail end of the oil bank after $t_{\mathrm{DT}}=2 \mathrm{PV}$ when the oil cut is low. This might be because of the lower permeability value for this section (6.7 $\mathrm{mD}$ ) compared to $7.3 \mathrm{mD}$ and $8.1 \mathrm{mD}$, respectively, for Sects. 1 and 2 of the core. Pore volume available to mobile oil is $26 \%$, while the calculated $S_{\text {gas }_{t}{ }_{{ }_{\mathrm{D} 1}}}$ is $29 \%$. The high

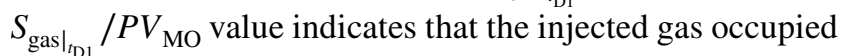
most of the high-permeability pores, enabling the liquid to reach less accessible, low-permeability pores.

The early stages of the LTG flood is characterized by higher pressure drop compared to the waterflood. This is because of the buildup of the oil bank plus the effect of reduced apparent mobility of the injected phases due to the propagation of foam. At later stages (after $t_{\mathrm{DT}}=2 \mathrm{PV}$ ), the pressure curves are impacted by the effect of oil desaturation. The pressure drop at $S_{\text {orw }}$ is higher at residual oil saturation than that of the LTG flood $\left(S_{\text {orLTG }}\right)$, while $S_{\text {orw }}$ (38\%) is higher than $S_{\text {orLTG }}(5.7 \%)$.

\subsubsection{Effect of slug injection salinity (Coreflood 2)}

The only difference between Corefloods 2 and 1 was that the slug injection salinity in Coreflood 2 was at the boundary between Type I and Type III (130,000 ppm), unlike the optimum Type III salinity $(148,000 \mathrm{ppm})$ in Coreflood 1 . Jong et al. (2016) experimentally observed that injection at sub-optimum salinity is better for oil recovery in higher-permeability rocks. These experiments were done in sandstone rocks at low formation and injection salinity. Therefore, it is necessary to investigate the effect of slug injection salinity in low-permeability, high-salinity, carbonate rocks. In the field scale, it is generally preferable to inject the slug at a higher salinity which is closer to the waterflood/produced water salinity. But if generous quantity of fresh water is available, it might be preferable to inject the slug at a lower salinity which is closer to the fresh water salinity.

The ultimate oil recovery in Coreflood 2 was $80 \%$ ROIP as compared to $85 \%$ in Coreflood 1. Even though the ultimate recovery is not very different, the rate of oil recovery is strikingly lower in Coreflood 2 (Fig. 7a). The initial oil cut for Coreflood 2 is also comparatively lower than that of Coreflood 1. At the end of slug injection $\left(t_{\mathrm{DT}}=1 \mathrm{PV}\right)$, only $22 \%$ ROIP was recovered. Because of faster oil recovery in Coreflood 1, the oil bank is shorter with higher oil cut, while Coreflood 2 has a more elongated oil bank with lower oil cut. The effluent salinity profile for Coreflood 2 is much more gradual than Coreflood 1(Fig. 7b). This is because of the slightly higher in situ oil saturation for extended time in Coreflood 2. As a result, the pore volume available for mixing between the resident brine and the injected brine is reduced, leading to slower transition from higher to lower salinity. Note that the pressure drop between Coreflood 1 and Coreflood 2 was almost the same, close to $70 \mathrm{psi} / \mathrm{ft}$, during buildup of oil bank. After oil bank breakthrough, the pressure drop for both was around $45 \mathrm{psi} / \mathrm{ft}$. According to Jong et al. (2016), improved mobility control afforded by keeping slug injection salinity at Type I-Type III boundary was the dominant factor compared to oil-water IFT reduction afforded by injecting the slug at optimum Type III salinity in permeable rocks (400-500 mD). However, for low-permeability rocks, the presence of ultra-low IFT corresponding to Type III optimum salinity was crucial right from the beginning of slug injection. One of the reasons is that the capillary pressure is much higher for such low-permeability rocks. To overcome this capillary pressure and mobilize the trapped oil, the oil-water IFT needs to be as low as possible. This can only happen efficiently when the slug is injected at Type III optimum salinity. 

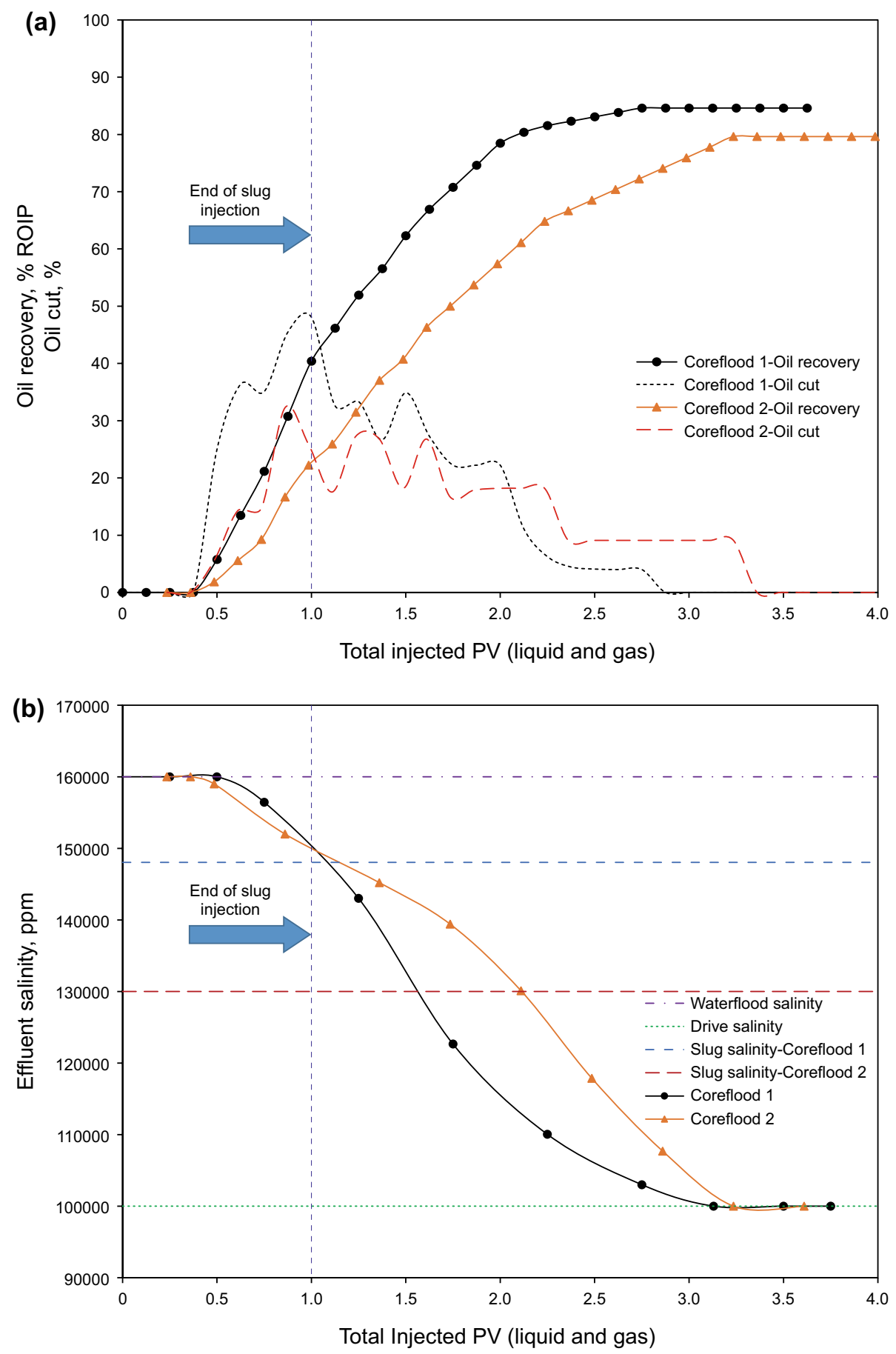

Fig. 7 a Oil recovery and oil cut and $\mathbf{b}$ effluent salinity for Corefloods 1 and 2

\subsubsection{Effect of lower surfactant concentration (Coreflood 3)}

The effect of reducing the surfactant concentration in slug by half was studied in Coreflood 3. All the injection parameters are similar to Coreflood 1 except for lower surfactant concentration.
Oil recovery values and rates are very similar for both corefloods (Fig. 8a). The ultimate recovery is only slightly lower at 80\% ROIP in Coreflood 3. From the similar effluent salinity curves (Fig. 8b), it is seen that dispersion characteristics are also almost identical in Corefloods 1 and 3 . Coreflood 3 also exhibits high $S_{\text {gas }_{t_{\mathrm{D} 1}}} / P V_{\mathrm{MO}}$ value associ- 

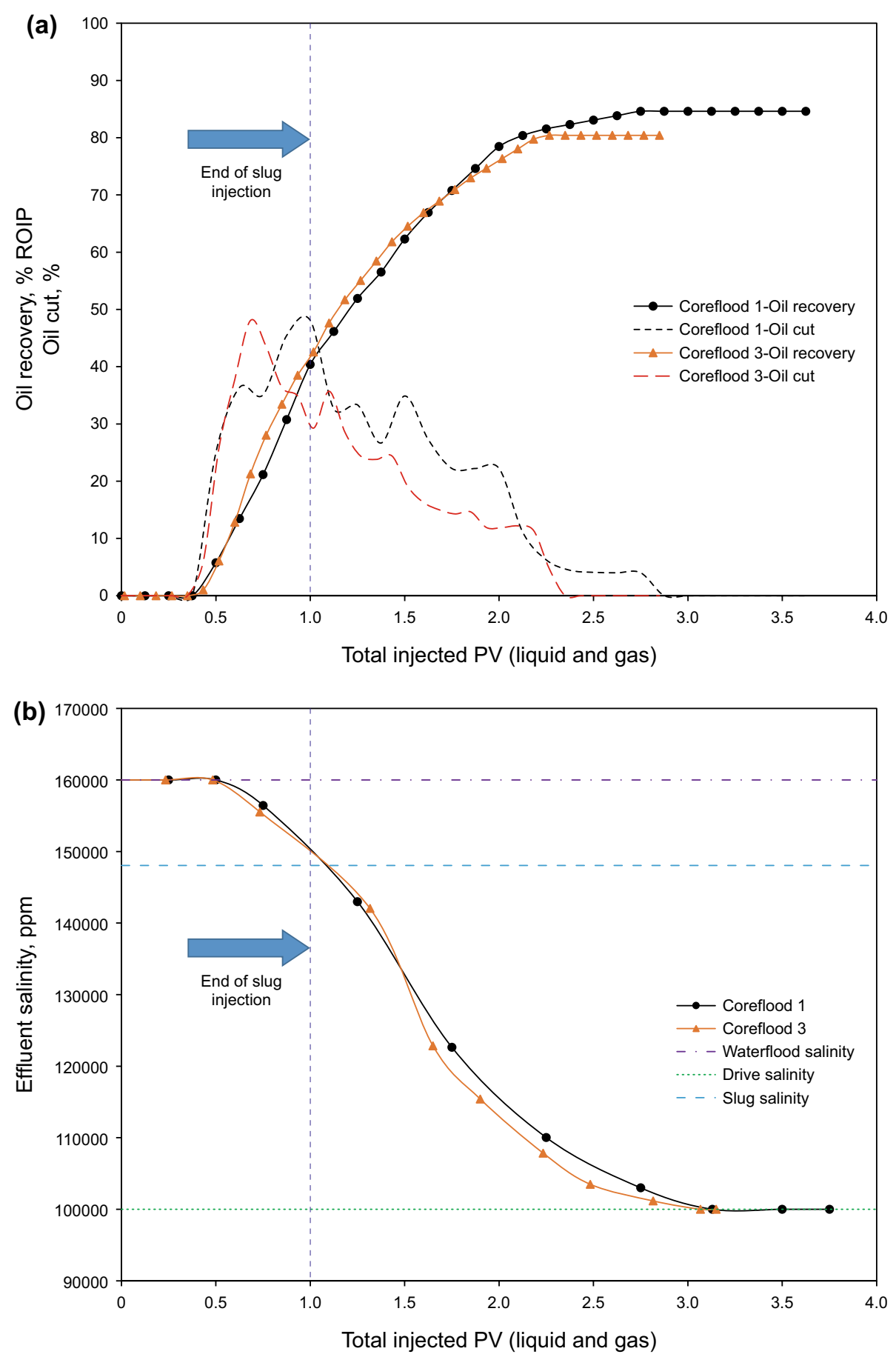

Fig. 8 a Oil recovery and oil cut and $\mathbf{b}$ effluent salinity for Corefloods 1 and 3

ated with higher and faster rates of oil recovery. Pore volume available to mobile oil is $29 \%$, while calculated $S_{\text {gas }\left.\right|_{t_{\mathrm{D} 1}}}$ is $30 \%$. From this coreflood, it can be hypothesized that for a particular foam quality, there exists a limiting value of the injected surfactant concentration, above which the oil recovery rate and ultimate oil recovery value do not change, and that the optimum injected foam quality is affected by the injected surfactant concentration. In other words, if the surfactant is co-injected at reduced concentration with gas at a particular optimum foam quality, the oil recovery can be increased. 


\subsubsection{Effect of lower foam quality (Coreflood 4)}

In Coreflood 4, the injected slug surfactant concentration was reduced by half as compared to the other corefloods (only $0.25 \mathrm{wt} \%$ ). On the other hand, the injected foam quality was 30\% throughout slug and drive injection. The results are analyzed with respect to Coreflood 3. Figure 9 shows that even though the injected surfactant concentration was reduced by half, the ultimate oil recovery in Coreflood 4 was still 65\% ROIP as compared to 80\% ROIP in Coreflood 3. Additionally, the oil cut in Coreflood 4 was not as high as in Coreflood 3; it was still consistent between $10 \%$ and $20 \%$. Both Corefloods 3 and 4 reached the ultimate oil recovery value around $t_{\mathrm{DT}}=2 \mathrm{PV}$.

When surfactant is injected into the core, it is partially subjected to adsorption, while also contributing to the lower of oil-water IFT by forming microemulsion. As such, the amount of surfactant that is available for stabilizing foam is reduced. This poses a big problem when the total surfactant injected is reduced substantially. In this case, the surfactant available to assist in foam stability and mobility control is considerably reduced. In such a scenario, lowering injection foam quality may help improve foam stability due to the formation of wet foam as many previous foam studies have shown that the apparent viscosity of foam could increase with a decrease in foam quality (Alvarez et al. 2001; Osterloh and Jante 1992; Simjoo et al. 2013). This strategy is important for preventing a severe loss of fluid mobility control, where a very small amount of ultra-low IFT inducing surfactant is injected. This may explain the observation that a decrease in slug surfactant concentration by $75 \%$ in Coreflood 4 as compared to the reference Coreflood 1 resulted in only $20 \%$ decrease in oil recovery with a reduction in foam quality from $50 \%$ to $30 \%$.

\section{Conclusions}

LTG flooding was established to be an attractive tertiary recovery method for low-permeability $(<10 \mathrm{mD})$ carbonate reservoirs with high formation brine salinity and high concentration of divalent cations $\left(\mathrm{Ca}^{2+}\right.$ and $\left.\mathrm{Mg}^{2+}\right)$. A surfactant formulation was designed using novel nonionic surfactant alkyl polyglucoside (APG) which exhibited ultra-low IFT, good aqueous stability and foam stabilization properties. Measured oil-water IFT values for Type I microemulsion were as low as $10^{-3}$ dyne/cm, indicating an efficient formulation for oil mobilization. A design was employed for drive injection using only APG which appeared to provide good foam stability and ensure aqueous phase integrity even in the presence of high-salinity brine. Oil recovery up to $85 \%$ ROIP and $90.9 \%$ OOIP was achieved by using LTG flooding for tertiary recovery, with final $S_{\text {or }}$ after LTG flooding as low as $5.7 \%$. Steady progression of the oil bank through the core was observed from pressure drop data. Steady-state pressure drop for LTG flood was lower than that of waterflood.

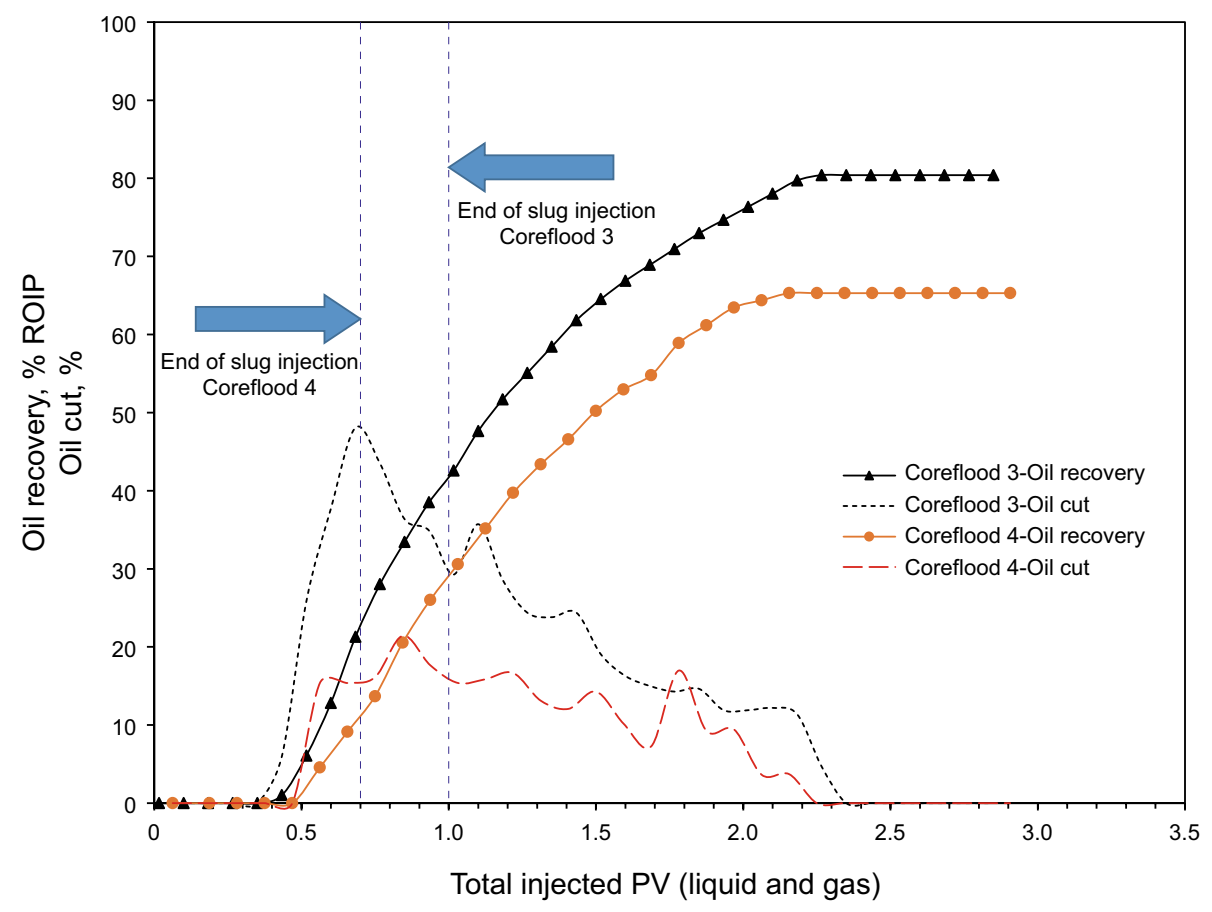

Fig. 9 Oil recovery and oil cut for Corefloods 3 and 4 
Studies of the impact of solubilized oil on foam stability confirmed past research findings. In the Type I microemulsion regime, an increase in salinity led to an increase in volume of solubilized oil and increased size of oil-swollen micelles. The reduced inter-micellar repulsion because of larger, disperse oil-swollen micelles was detrimental to the ordered structuring of micelles necessary for the stepwise thinning of film lamellae, which reduced the foam stability.

For low-permeability rocks, injecting slug at optimum Type III salinity exhibited higher oil production rates than injecting at the boundary between Type I and Type III microemulsion. High oil recovery was maintained even after reducing the injected surfactant concentration by $75 \%$. This was possible by tailoring the injected foam quality according to the reduced surfactant concentration. Further research will be conducted to understand better the correlation between surfactant concentration and foam quality.

Acknowledgements This research is supported by Petroleum Development Oman and Shell Global Solutions International. We would like to thank Shell GSI for sponsoring this research and giving us permission to publish the results.

Open Access This article is licensed under a Creative Commons Attribution 4.0 International License, which permits use, sharing, adaptation, distribution and reproduction in any medium or format, as long as you give appropriate credit to the original author(s) and the source, provide a link to the Creative Commons licence, and indicate if changes were made. The images or other third party material in this article are included in the article's Creative Commons licence, unless indicated otherwise in a credit line to the material. If material is not included in the article's Creative Commons licence and your intended use is not permitted by statutory regulation or exceeds the permitted use, you will need to obtain permission directly from the copyright holder. To view a copy of this licence, visit http://creativecommons.org/licenses/by/4.0/.

\section{References}

Abalkhali NA, Liyanage PJ, Upamali KA, Pope GA, Mohanty KK. ASP flood application for high-temperature, high-salinity carbonate reservoir. In: SPE Middle East oil and gas show and conference, Manama, Bahrain, 18-21, 2019. https://doi.org/10.2118/19494 8-MS.

Adkins S, Arachchilage GP, Solairaj S, Lu J, Weerasooriya U, Pope G. Development of thermally and chemically stable large-hydrophobe alkoxy carboxylate surfactants. In: SPE Improved Oil Recovery symposium in Tulsa, Oklahoma, USA, 14-18 April, 2012. https://doi.org/10.2118/154256-MS.

Alvarez JM, Rivas HJ, Rossen WR. Unified model for steady-state foam behavior at high and low foam qualities. SPE J. 2001;6(3):325-33. https://doi.org/10.2118/74141-PA.

Balan HO. Dynamics of foam mobility in porous media. PhD Dissertation. Austin: The University of Texas at Austin; 2013.

Barnes JR, Smit J, Smit J, Shpakoff G, Raney KH, Puerto M. Development of surfactants for chemical flooding at difficult reservoir conditions. In: SPE/DOE Improved Oil Recovery symposium, Tulsa, Oklahoma, 19-23 April, 2008. https://doi.org/10.2118/11331 3-MS.
Barnes JR, Dirkzwager H, Smit J, Smit J, On A, Navarrete RC, Buijse MA. Application of internal olefin sulfonates and other surfactants to EOR. Part 1: structure-performance relationships for selection at different reservoir conditions. In: SPE Improved Oil Recovery, Tulsa, Oklahoma, 24-28 April, 2010. https://doi. org/10.2118/129766-MS

Buijse MA, Prelicz RM, Barnes JR, Cosmo C. Application of internal olefin sulfonates and other surfactants to EOR. Part 2: the design and execution of an ASP field test. Presented at the SPE Improved Oil Recovery, Tulsa, Oklahoma, 24-28 April, 2010. https://doi. org/10.2118/129769-MS

Conn CA, Ma K, HirasakiGJ BiswalSL. Visualizing oil displacement with foam in a microfluidic device with permeability contrast. Lab Chip. 2014;14(20):3968-77. https://doi.org/10.1039/ C4LC00620H.

Cottin C, Morel D, Levitt D, Cordelier P, Pope G. Alkali surfactant gas injection: attractive laboratory results under the harsh salinity and temperature conditions of middle east carbonates. In: Abu Dhabi International petroleum exhibition and conference, Abu Dhabi, 11-14 November 2012. https://doi. org/10.2118/161727-MS.

Das A, Nguyen N, Alkindi A, et al. Low tension gas process in high salinity and low permeability reservoirs. In: SPE EOR conference at oil and gas West Asia, Muscat, Oman, 21-23 March, 2016. https://doi.org/10.2118/179839-MS.

El-Dessouky HT, Ettouney HM. Fundamentals of salt water desalination. Amsterdam: Elsevier; 2002.

Farajzadeh R, Lotfollahi M, Bedrikovetsky P. Simultaneous sorption and mechanical entrapment during polymer flow through porous media. In: SPE Kuwait oil \& gas show and conference, Mishref, Kuwait, 11-14 October, 2015. https://doi.org/10.2118/17538 0-MS.

Flaaten AK, Nguyen QP, Zhang J, et al. ASP chemical flooding without the need of soft water. In: SPE annual technical conference and exhibition, Denver, Colorado, USA, 21-24 September, 2008. https ://doi.org/10.2118/116754-MS.

Ghosh B, Obassi D. Eco-friendly surfactant for EOR in high temperature, high salinity carbonate reservoir. In: SPE Enhanced Oil Recovery conference, Kuala Lumpur, Malaysia, 2-4 July, 2013. https://doi.org/10.2118/165219-MS.

Hirasaki GJ, van Domselaar HR, Nelson RC. Evaluation of the salinity gradient concept in surfactant flooding. SPE J. 1983;23(3):486500. https://doi.org/10.2118/8825-PA.

Huh C. Equilibrium of a microemulsion that coexists with oil or brine. SPE J. 1983;23(5):829-47. https://doi.org/10.2118/10728-PA.

Iglauer S, Wu Y, Shuler PJ, et al. Alkyl polyglucoside surfactants for improved oil recovery. In: SPE/DOE fourteenth symposium on improved oil recovery, Tulsa, Oklahoma, 17-21 April, 2004. https ://doi.org/10.2118/89472-MS.

Jong $\mathrm{S}$. Investigating the impact of salinity gradient design on low tension gas flooding performance. Master's Thesis. Austin: The University of Texas at Austin; 2018.

Jong S, Nguyen NM, Nghiem LX, et al. Low tension gas flooding as a novel EOR method: an experimental and theoretical investigation. In: SPEIOR conference, Tulsa, USA, 11-13 April, 2016. https:// doi.org/10.2118/179559.

Kamal M, Marsden SS, Jr. Displacement of a micellar slug foam in unconsolidated porous media. In: The 48th annual fall meeting of the Society of Petroleum Engineers of AIME, Las Vegas, Nevada, 30 September-3 October, 1973. https://doi.org/10.2118/4584.

Kamal MS, Hussein IA, Sultan AS. Review on surfactant flooding: phase behavior, retention, IFT and field applications. Energy Fuels. 2017;31(8):7701-20. https://doi.org/10.1021/acs.energ yfuels.7b00353.

Kennedy DK, Kitziger FW, Hall BE. Case study of the effectiveness of nitrogen foam and water-zone diverting agents in multistage 
matrix acid treatments. SPE Prod Eng. 1992;7(02):203-11. https ://doi.org/10.2118/20621-PA.

Koczo K, Lobo LA, Wasan DT. Effect of oil on foam stability: aqueous foams stabilized by emulsions. J Colloid Interface Sci. 1992;150(2):492-505. https://doi.org/10.1016/00219797(92)90218-B.

Lawson JB, Reisberg J. Alternate slugs of gas and dilute surfactant for mobility control during chemical flooding. In: The first joint SPE/ DOE symposium on enhanced oil recovery, Tulsa, Oklahoma, 20-23 April, 1980. https://doi.org/10.2118/8839-MS.

Levitt DB, Jackson AC, Heinson C, et al. Identification and evaluation of high performance EOR surfactants. SPE J. 2009;12(2):243-53. https://doi.org/10.2118//100089-PA.

Li RF, Yan W, Liu S, Hirasaki GJ. Foam mobility control for surfactant EOR. In: 2008 SPE/DOE Improved Oil Recovery symposium, Tulsa, Oklahoma, 19-23 April, 2008. https://doi. org/10.2118/113910-MS.

Lobo LA, Nikolov AD, Wasan DT. Foam stability in the presence of oil: on the importance of the second virial coefficient. J Dispers Sci Technol. 1989;10(2):143.

Lu J, Britton C, Solairaj S, Liyanage PJ, Kim DH, Adkins S, et al. Novel large-hydrophobe alkoxy carboxylate surfactants for enhanced oil recovery. In: SPE Improved Oil Recovery symposium, Tulsa, Oklahoma, USA, 14-18 April, 2014. https://doi. org/10.2118/154261-Ms.

Manlowe DJ, Radke CJ. A pore-level investigation of foam/oil interactions in porous media. SPE Reserv Eng. 1990;5(4):495-502. https ://doi.org/10.2118/18069-PA.

Metin C, Bonnecaze RT, Nguyen QP. The viscosity of silica nanoparticle dispersions in permeable media. SPE Reserv Eval Eng. 2013;16(3):327-32. https://doi.org/10.2118/157056-PA.

Nelson RC, Pope GA. Phase relationships in chemical flooding. SPE J. 1978;18(5):325-38. https://doi.org/10.2118/6773-PA.

Nguyen QP, Currie PK, Zitha PLJ. Effect of crossflow on foam-induced diversion in layered formations. SPE J. 2005;10(1):54-65. https:// doi.org/10.2118/82270-PA.

Nguyen QP, Zitha PLJ, Currie PK, Rossen WR. CT study of liquid diversion with foam. SPE Prod Oper. 2009;24(1):12-21. https:// doi.org/10.2118/93949-PA.

Nikolov AD, Wasan DT. Ordered micelle structuring in thin films formed from anionic surfactant solutions (I) experimental. J Colloid Interface Sci. 1989;133(1):1-12. https://doi. org/10.1016/0021-9797(89)90278-6.

Nikolov AD, Kralchevsky PA, Ivanov IB, Wasan DT. Ordered micelle structuring in thin films formed from anionic surfactant solutions (II) model development. J Colloid Interface Sci.
1989;133(1):13-22. https://doi.org/10.1016/0021-9797(89)90279 $-8$.

Osterloh WT, Jante MJ Jr. Effects of gas and liquid velocity on steadystate foam flow at high temperature. In: SPE/DOE Enhanced Oil Recovery Symposium, 22-24 April, Tulsa, Oklahoma, 1992. https ://doi.org/10.2118/24179-MS.

Pope GA, Wang B, Tsuar K. A sensitivity study of micellar/ polymer flooding. SPE J. 1979;19(6):357-68. https://doi. org/10.2118/7079-PA.

Simjoo M, Dong Y, Andrianov A, Talanana M, Zitha PL. Novel insight intofoam mobility control. SPE J. 2013;18(3):416-27. https://doi. org/10.2118/163092-PA.

Solairaj S. New method of predicting optimum surfactant structure for EOR. Master's Thesis. Austin: The University of Texas at Austin; 2011.

Southwick JG, van den Pol E, van Rijn CHT, van Batenburg DW, Manap AA, Mastan AK, et al. Surfactant flooding in offshore environments. In: SPE Improved Oil Recovery conference, Tulsa, Oklahoma, 14-18 April, 2018. https://doi.org/10.2118/19029 6-MS.

Srivastava M, Zhang J, Nguyen QP, et al. A systematic study of alkaline-surfactant-gas injection as an EOR Technique. In: SPE annual technical conference and exhibition, New Orleans, Louisiana, USA, 4-7 October, 2009. https://doi.org/10.2118/124752-MS.

Srivastava M, Nguyen QP. Application of gas for mobility control in chemical EOR in problematic carbonate reservoirs. In: SPE Improved Oil Recovery symposium, Tulsa, Oklahoma, USA, 24-28 April, 2010. https://doi.org/10.2118/129840-MS.

Srivastava M. Foam assisted low interfacial tension enhanced oil recovery process. PhD Dissertation. Austin: The University of Texas at Austin; 2010.

Szlendak SM, Nguyen N, Nguyen QP. Laboratory investigation of lowtension-gas flooding for improved oil recovery in tight formations. SPE J. 2013;18(5):851-66. https://doi.org/10.2118/159841-PA.

Szlendak SM, Nguyen N, Nguyen QP. Investigation of localized displacement phenomenon for low-tension-gas (LTG) injection in tight formations. J Pet Sci Eng. 2016;142:36-45. https://doi. org/10.1016/j.petrol.2016.01.042.

Upamali KAN, Liyanage PJ, et al. New surfactants and co-solvents increase oil recovery and reduce cost. In: SPE Improved Oil Recovery conference, Tulsa, Oklahoma, 11-13 April, 2016. https ://doi.org/10.2118/179702-MS.

Wang D, Cheng J, Yang Z, et al. Successful field test of the first ultralow interfacial tension foam flood. In: SPE Asia Pacific Improved Oil Recovery conference, Kuala Lumpur, Malaysia, 8-9 October, 2001. https://doi.org/10.2118/72147-MS. 